\title{
Image
}

\section{Lost in the stomach}

\author{
Celine Aslinia, Steven Strickler, Florence Aslinia
}

Department of Gastroenterology, Bloomington Digestive Health, Bloomington, Indiana, US

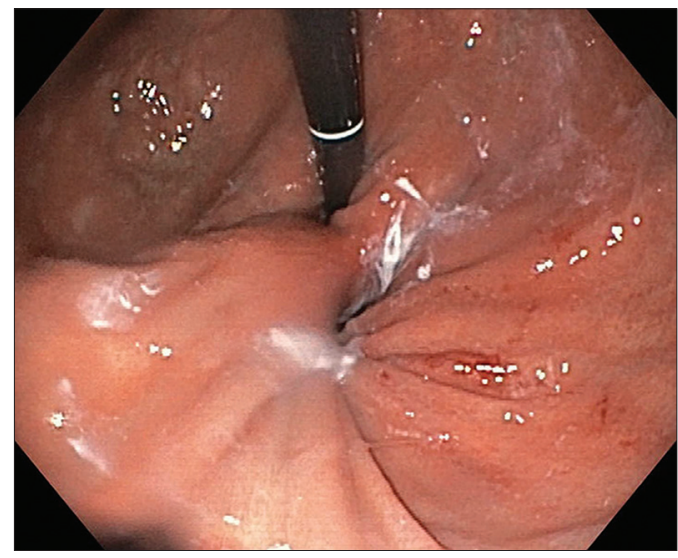

Figure 1: A small orifice close to the gastroesophageal junction on retroflexed view, while the forward view of the stomach only revealing a small pouch without outlet

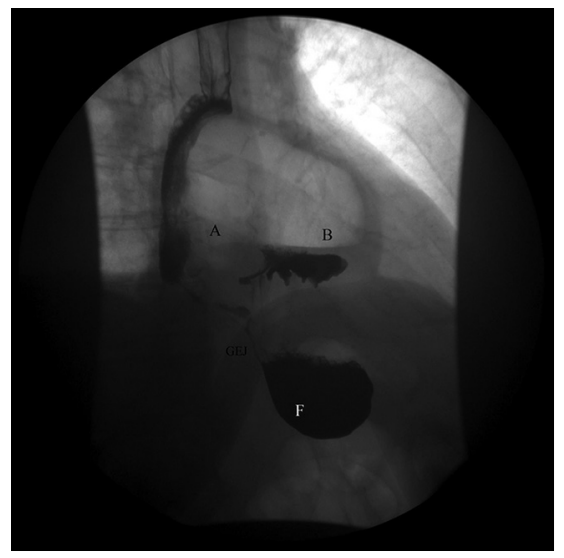

Figure 2: A large para-esophageal hernia on barium study with the fundus ( $F$ ) slightly shifted inferiorly and the gastric body (B) and the antrum $(A)$ rotated superiorly along its long axis into the para-esophageal hernia

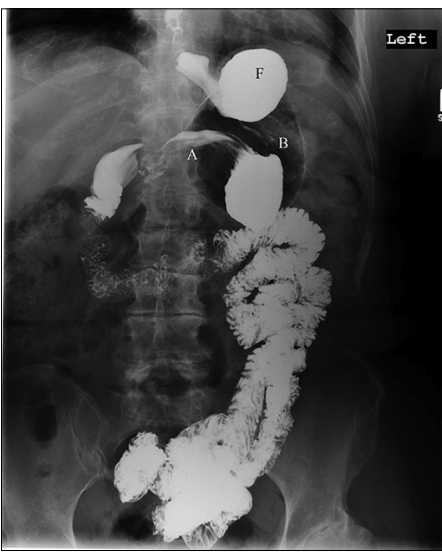

Figure 3: Overhead images of the abdomen after barium ingestion and reduction of the gastric volvulus showing the gastric antrum (A) still slightly rotated superiorly, with the fundus (F) and the gastric body (B) in the right position
Endoscopic retroflexed view of the stomach and gastric upper $\mathrm{Gl}$ images in a 71-year-old woman with intermittent post-prandial epigatric and left upper quadrant abdominal pain and unintentional weight loss.

What is the diagnosis?

Address for correspondence:

Ms. Celine Aslinia, Bloomington Digestive Health, 2205 W Sudbury Dr. Suite A, Bloomington, IN 47403, US.

E-mail: bloomingtondigestivehealth@gmail.com

\section{Access this article online}

Website:

www.jdeonline.in

DOI:

$10.4103 / 0976-5042.180100$
Quick Response Code

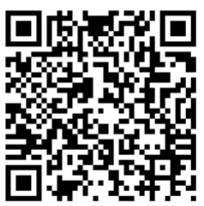

Image provided by:

Dr. Florence Aslinia

Bloomington, Indiana, US

Email: asliniaflorence@gmail.com
This is an open access article distributed under the terms of the Creative Commons Attribution-NonCommercial-ShareAlike 3.0 License, which allows others to remix, tweak, and build upon the work non-commercially, as long as the author is credited and the new creations are licensed under the identical terms.

For reprints contact: reprints@medknow.com

How to cite this article: Aslinia C, Strickler S, Aslinia F. Lost in the stomach J Dig Endosc 2016;7:36-7. 


\section{Answer}

A 71-year-old woman presented to the endoscopy unit through the open access for the evaluation of post-prandial epigatric and left upper quadrant abdominal pain for several months resulting in weight loss. Physical examination was unremarkable without tenderness over the upper abdomen. On endoscopy, the forward view of the stomach appeared completely abnormal. As the endoscope traversed the gastroesophageal junction (GEJ), the stomach appeared to be a small blind pouch without outlet or any trace of the gastric body or the antrum. A retroflexion was performed which revealed a small orifice close to the gastroesophageal junction [Figure 1]. This was intubated after various maneuvers such as clockwise and counterclockwise rotation of the endoscope and reduction of its length inside the blind pouch on retroflexed position. The endoscope could not be advanced farther due to the twisted position, but a brief look beyond the orifice revealed the normal appearance of the mucosa of the gastric body. Immediately after discharge from the endoscopy unit, the patient underwent an upper gastrointestinal series to further evaluate the anatomy of the twisted stomach. On the initial imaging of the stomach, there was a large para-esophageal hernia with the fundus $(\mathrm{F})$ slightly shifted inferiorly and the gastric body (B) and the antrum (A) rotated superiorly along its long axis into the paraesophageal hernia [Figure 2].
After the patient drank effervescent crystals and additional barium in an upright position, the herniation of the body into the para-esophageal hernia was reduced, as captured fluoroscopically by visualizing the change in the position of the gastric antrum The overhead images revealed that the gastric antrum was still slightly rotated superiorly [Figure 3]. She remained asymptomatic and was subsequently referred for elective surgery to prevent complete volvulus, ischemia, and infarction.

Gastric volvulus occurs uncommonly and may result in acute or recurring abdominal pain. This could be a diagnostic dilemma for both gastroenterologists and radiologists. As in the above case, individuals with para-esophageal hernia are prone to having a secondary rotation along the long axis of the stomach, resulting in organo-axial volvulus. This case presented several important points about gastric volvulus: First, patients with partial gastric volvulus ( $<180$ rotation along the axis) may present with mild and intermittent symptoms such as post-prandial abdominal pain and weight loss. Secondly, the endoscopic appearance of the stomach was hard to interpret without knowledge of the existing volvulus. Third, the volvulus was reduced by barium ingestion. This may be considered a new approach to reduce acute gastric volvulus as a temporary measure or in patients who are not eligible for immediate surgical intervention. Operative repair is recommended to avoid future ischemia and infarction. 